\title{
Interação e coletividade: apontamentos etnográficos sobre uma roda de choro
}

Interaction and collectivity: ethnographic notes about a roda de choro

Renan Moretti Bertho ${ }^{1}$ Universidade Estadual de Campinas - Unicamp renanbertho@gmail.com 


\section{Resumo}

A música praticada em uma roda de choro está sujeita às consequências diretas e indiretas da interação e da coletividade. No presente artigo busco demonstrar como este fazer musical proporciona formas simultâneas de negociação, promove tomadas instantâneas de decisões e oferece possibilidades singulares de organização. Teoricamente, dialogo com autores da área de etnomusicologia que apresentam discussões sobre fazer musical coletivo e suas possíveis relações entre música e sociedade. Posteriormente, apresento dados etnográficos construídos ao longo da minha pesquisa de campo, enfatizando, sobretudo, propostas de negociação, dinâmicas de revezamento, revezamentos entre músicos e diretrizes para a escolha dos instrumentos que serão tocados.

Palavras-chave: etnomusicologia; interação; coletividade; etnografia; rodas de choro

\section{Abstract}

The music practiced on a roda de choro is subject to direct and indirect consequences of the interaction and the collectivity. In this article, I seek to demonstrate how this music making provides simultaneous forms of negotiation, promotes instant decisions and offers unique possibilities of organization. Theoretically, I dialogue with authors of ethnomusicology who discuss music making and its possible relations between music and society. Later, I present ethnographic data constructed during my fieldwork, emphasizing negotiation proposals, dynamics of alternation between musicians, and guidelines for choosing the instruments that will be played.

Keywords: ethnomusicology; interaction; collectivity; ethnography; rodas de choro

Doutorando em Música pela Universidade Estadual de Campinas (Unicamp). Possui mestrado em Música pela mesma instituição (2015) e graduação em Educação Musical pela Universidade Federal de São Carlos (2008). Desenvolve a pesquisa "Trilhas do choro: entre o participativo e o apresentacional nas rodas do interior paulista" (bolsa FAPESP) e ocupa o cargo de $2^{\circ}$ Tesoureiro da Associação Brasileira de Etnomusicologia - ABET - gestão 2017/2019. 


\section{1-) Introdução}

Gostaria de iniciar com três exemplos de performance musical para a polca Atraente, composta por Chiquinha Gonzaga em 1877:

1-) Um acordeonista tocando sozinho no palco de um teatro;

2-) O mesmo acordeonista, no palco do mesmo teatro, mas desta vez acompanhado de um cavaquinista, um pandeirista e um violonista;

3-) Os mesmos quatro músicos, agora sentados na praça que fica em frente ao teatro e desta vez participando de uma roda de choro?

A maneira como esses músicos interagem ao tocar Atraente em diferentes situações é o ponto de partida para o presente texto. Na primeira situação, o acordeonista solo interage com o seu instrumento e com seu público; já na segunda situação, além das ações já mencionadas, temos o acordeonista interagindo com os músicos que o acompanham, cada qual interagindo com os outros músicos presentes no palco, estes interagindo com seus respectivos instrumentos e ainda a interação dos instrumentistas com o público; enquanto isso, na roda de choro, além das interações descritas até o momento, os mesmos quatro músicos estão sujeitos às interações imprevistas, que são características próprias de uma performance participativa (é o que acontece, por exemplo, quando outros instrumentistas chegam, ocupam um lugar na roda e começam a tocar - muitas vezes no meio da música! - sem nem ao menos anunciar sua presença ou combinar previamente os detalhes desta participação). Há de se mencionar ainda alguns imprevistos que fazem parte da dinâmica da própria praça onde a roda acontece: o casal que está dançando e acidentalmente esbarra no ombro de um músico; o carro cujo alarme dispara, atrapalhando a concentração dos envolvidos; o vendedor ambulante que anuncia em voz alta o preço do amendoim, entre outras casualidades 3 .

Diante destes três exemplos, meu argumento é que, quando os formatos de apresentação musical se alteram, também se alteram as consequências diretas e indiretas da interação e da coletividade que influenciam e determinam a performance. Em outras palavras, em cada uma das três situações, a performance da polca Atraente está sujeita a diferentes formas de negociação e de organização, bem como de instabilidades consequentes de cada um dos contextos. Estes aspectos nem sempre são intencionais e muitas vezes são difíceis de serem percebidos, mas o fato é que os músicos precisam encontrar maneiras de lidar com estas condições e de organizar a prática musical em situações distintas. Logo, a interação e a coletividade não são índices fixos, que podem ser calculados ou previstos; mais do que isso, são variáveis que estão sujeitas às questões estruturais, bem como às normas sociais e culturais de cada performance.

\footnotetext{
2 Além dos choros, propriamente ditos, o repertório destas rodas envolve variados ritmos e gêneros musicais, tais como valsas, maxixes e polcas, que é o caso de Atraente.

3 Convém esclarecer que incidentes e eventualidades não acontecem somente na roda de choro. Mesmo um pianista solista, em um ambiente com reduzidas interferências externas, pode se deparar com um piano inadequado ou uma sala de concerto com acústica ruim (CHAFFIN et al., 2006, p.200). Logo, imprevistos podem acontecer nas três situações descritas no início do texto.
} 
Dito isto, busco fundamentação teórica nas propostas de John Blacking, Anthony Seeger, Thomas Turino, Suzel Reily e Martin Clayton, autores que, em maior ou menor grau, discutiram o fazer musical coletivo, bem como as possíveis relações entre música e sociedade. Não por acaso, a presença destes nomes representa um viés histórico de como a etnomusicologia encarou o debate sobre o fazer musical coletivo em diferentes momentos da história da disciplina. Desde as reflexões de John Blacking feitas na década de 1970 sobre a prática coletiva da tshikona na comunidade sul-africana Venda, a etnomusicologia manteve um lugar cativo para o debate sobre a importância de fazer música em conjunto. Com a consistência deste debate no mundo contemporâneo, podemos observar propostas metodológicas para o mapeamento das sincronias que se dão entre os músicos que tocam juntos. É o caso, por exemplo, das abordagens de Martin Clayton, que mesclam sistemas dinâmicos de interação e perspectiva etnográfica da performance musical.

Os dados etnográficos apresentados no último tópico foram construídos em uma roda de choro da cidade de São Carlos/SP, ao longo de minha pesquisa e mestrado 4 . Trata-se de um material construído a partir da escrita sistemática do diário de campo, de entrevistas semiestruturadas e de observações participantes, realizadas entre julho de 2013 e dezembro de 2014, período no qual observei atentamente questões como gestos, expressões corporais, percepção dos sons, formas de participação, entre outras condutas habituais. No presente texto, minha intenção é utilizar alguns destes dados para descrever os variados processos de interação e as múltiplas situações coletivas que ocorrem em uma roda de choro, na tentativa de esboçar uma resposta às seguintes questões: como se dão as situações de interação que fazem dos choros praticados nas rodas uma música coletiva? Como é a colaboração e a interação entre os envolvidos neste processo? Quais são as características e as peculiaridades desta coletividade? 0 caminho para construção das respostas passa, sobretudo, pela análise das propostas de negociação, das dinâmicas de revezamento e focaliza ainda ações como os revezamentos entre músicos e as diretrizes para a escolha dos instrumentos.

\section{2-) Perspectivas teóricas}

Entre 1956 e 1958, John Blacking conviveu com os Venda, uma comunidade sul-africana na qual pesquisou os cantos infantis. Entre os diversos exemplos de experiência coletiva presente na música desta comunidade, o autor destaca o alto grau de cooperação necessária para performance da tshikona, uma prática musical coreografada que só pode ser realizada com mais de vinte participantes tocando flautas de diferentes afinações com extrema exatidão (BLACKING, 1973, p.51). O argumento principal de Blacking é que a tshikona apresenta um envolvimento intensificado entre os participantes, portanto não se trata apenas de quantidade, mas sobretudo de qualidade. Nas palavras

\footnotetext{
4 A pesquisa foi realizada entre 2013 e 2015 no Instituto de Artes da Unicamp, sob orientação da Profa. Dra. Lenita W. M. Nogueira e com apoio da FAPESP ( $n^{\circ}$ do processo 2013/08972-1). Como fruto desta, surgiu a dissertação intitulada Academia do Choro: Performance e fazer musical na roda.
} 
do autor, a beleza e a eficácia da tshikona só acontecem por conta da "qualidade das relações que são estabelecidas entre as pessoas e as tonalidades sempre que ela [a tshikona] é performada" (BLACKING, 1973, p.51).

Já em Music, Culture and Experience, Blacking argumenta em prol da performance musical como um "evento modelado em um sistema de interação social" (1995, p.227). De acordo com essa proposta, os significados da performance só podem ser compreendidos na relação com outros eventos do sistema. Como exemplo, o autor demonstra de que maneira as relações entre as estruturas musicais e os padrões da vida social e cultural o ajudaram a compreender como os Venda preparam as crianças para música adulta. Tal proposta é igualmente presente em How musical is man?, no momento em que o autor sugere uma interpretação estrutural para um contexto cultural total (BLACKING, 1973, p.21). Nestes termos, a análise de um determinado contexto levaria em conta relações entre os participantes da performance e seus respectivos meios, ou seja: "o som pode ser o objeto, mas o homem é o sujeito; e a chave para compreender a música está nas relações existentes entre sujeito e objeto" (BLACKING, 1973, p.26).

Ainda neste sentido, Elizabeth Travassos (2007, p.193) nos coloca que John Blacking estabeleceu um programa de pesquisa chamado "análise cultural da música". O autor apresenta uma postura crítica em relação às análises musicológicas formais e nos sugere um modelo que relaciona sistema musical com origem social (BLACKING, 1973, p.90-96). Esta análise é concebida por Blacking como uma teoria unificada, que aborda ao mesmo tempo cognição, sociedade, cultura e criatividade. Ou seja, "podemos aprender mais sobre música e musicalidade humana se olharmos para as leis básicas do comportamento musical, que são biologicamente, tanto quanto culturalmente, condicionadas e especificadas" (BLACKING, 1973, p.100). Em suma, o que Blacking demonstrou em diversos níveis é que, ao observarmos práticas musicais coletivas, estamos diante de elementos muito mais densos e profundos do que simplesmente o fator sonoro. Logo, o estudo e a análise da coletividade presente nestas práticas deve estar atrelado às relações que se dão entre os envolvidos, tanto quanto à sonoridade produzida por esses sujeitos.

Em Por que cantam os Kĩsêdjế, Anthony Seeger argumenta que as performances estabelecem, restabelecem e alteram a significação do fazer musical, determinando assim importantes relações entre indivíduos e grupos (2015, p.139). Neste sentido, o autor compreende o canto enquanto uma atividade criativa que perpassa a vida social da comunidade Kĩsêdjê. Metaforicamente, a aldeia é comparada a um teatro de arena, no qual "os sons produzidos em um canto do assentamento costumam se fazer audíveis para todos os seus membros" (SEEGER, 2015, p.140); a temporalidade é tida como um concerto, de modo que as atividades cerimoniais, responsáveis por estruturar o ano, "restabeleciam períodos de tempo e algumas das relações entre estes" (SEEGER, 2015, p.148); e a sociedade é comparada a uma orquestra que recebe a contribuição sonora, neste caso vocal, de diferentes indivíduos; em outras palavras, "seus sons eram complementares e juntos criavam a euforia da participação comunitária" (SEEGER, 2015, 
p.157). Mais do que ilustrar o papel do canto na comunidade Kĩsêdjê, as metáforas apresentadas por Seeger revelam como a aldeia se estrutura e se relaciona sonoramente, mostrando diferentes níveis de interação entre som, ambiente e ser humano. Nota-se ainda que a "euforia da participação comunitária" só é atingida quando o fazer musical transcende a atuação individual, só então é possível falar em uma prática coletiva que excede os limites convencionais de espaço e tempo daquela aldeia.

Suzel Reily, por sua vez, observa como acontecem as ações coordenadas, coletivas e participativas em grupos de Folias de Reis. Em Voices of the Magi a autora assinala que as jornadas dos grupos de folia fazem parte da vida cotidiana dos participantes, mas que também são "espaços especiais que engrandecem a experiência social através do fazer musical e da intensa sociabilidade" (REILY, 2002, p.1). A Folia de Reis é entendida como uma tradição religiosa musicalmente direcionada, na qual a música é uma maneira de organizar o comportamento coletivo. Inserida no contexto religioso, a performance musical participativa organiza, orienta e legitima a execução ritual, permitindo aos participantes entoar suas crenças "ao mesmo tempo em que suas interações coordenadas durante o fazer musical recriam os ideais sociais incorporados em seus princípios religiosos" (REILY, 2002, p.3).

Em diálogo com Max Weber, a autora propõe o conceito de encantamento, entendendo-o como um "modo musical de orquestração ritual" (REILY, 2002, p.3). Ao associar encantamento e moralidade no ambiente das folias, temos então uma profunda experiência transformadora por meio da "criação de um mundo social visionário moralmente fundamentado" (REILY, 2002, p.4), mundo este que toma forma por meio da criação musical coletiva, comunitária e participativa. As associações entre religião, moralidade, fazer musical e comunidade são o ponto de partida para Reily pensar como ocorrem as negociações e as trocas simbólicas ou materiais durante a performance ritual da Folia de Reis. Diante desta rede conceitual, a religião funciona como uma maneira de negociar interesses, e a música funciona como uma maneira de organizar o comportamento coletivo.

De volta à situação de abertura do presente texto, deve-se observar que os gestos que o acordeonista realiza durante a performance estão sincronizados entre si. Os dedos da mão direita, por exemplo, apresentam um complexo grau de sincronia, sendo imprescindível que cada dedo toque as teclas em seu devido tempo. Quando ele toca em conjunto com outras pessoas, observamos relações de sincronia para além do seu próprio corpo. Exemplificando, é possível haver sincronias com os braços do pandeirista ou ainda com as paletadas do cavaquinista. Ao pensar sobre a complexidade e os limites destes processos de sincronização, Martin Clayton propõe a utilização dos sistemas dinâmicos ou complexos para explicar estas ações. Em Entrainment, ethnography and musical interation, Clayton compreende sistemas dinâmicos como modelos utilizados para observar comportamentos autônomos que interagem entre si, levando em conta agentes e fatores independentes (2013, p.17). 
Entre as contribuições apresentadas por Clayton, está a teoria do embarcamento ${ }^{6}$, um modelo para compreensão de como sistemas rítmicos independentes interagem entre si. Em outras palavras, embarcamento é "o nome dado a um corpo teórico que busca explicar como processos rítmicos autônomos interagem. É um inestimável modelo na descrição dos processos de sincronização" (CLAYTON, 2013, p.20). Tal teoria é utilizada em várias áreas do conhecimento, como a biologia ao estudar as interações entre os seres vivos e o ambiente que habitam. O autor relata situações de embarcamento nas quais os níveis de sincronia podem variar de acordo com o contexto, ocasionando desde sentimentos de amizade e coesão social até a coordenação interpessoal das oscilações neurais. (CLAYTON, 2013, p.21-22). No caso específico de uma performance musical, encontramos estes comportamentos nas ações realizadas entre diferentes participantes em um mesmo evento, sendo possível identificar este fenômeno através do rastreamento de áudio, do reconhecimento dos padrões de movimento corporal, ou ainda por meio da identificação dos padrões de onda cerebral.

Dependendo do tipo de informação e dos dados disponibilizados, o embarcamento musical pode ser estudado em três diferentes níveis: intraindividual, interindividual e intergrupo. O primeiro nível trata das coordenações entre as partes do corpo de um instrumentista, como os dedos do acordeonista citado anteriormente. Neste exemplo, as habilidades motoras adquiridas previamente pelo músico se relacionam aos processos neurológicos inconscientes (CLAYTON, 2013, p.31). No nível interindividual, as sincronias podem ser observadas entre diferentes indivíduos de um mesmo grupo. Já o nível intergrupo ocorre quando há sincronia entre diferentes grupos.

\section{3-) Sobre choros e rodas}

Em meados do século XIX, por volta de 1870, músicos amadores, em sua maioria servidores públicos, advindos da alfândega, correio ou militares, reuniam-se para fazer música em situações festivas; assim surgiam as primeiras rodas de choro. Diversos autores $^{7}$ atribuem a origem desta manifestação ao Rio de Janeiro, que na época estava sob forte influência de ritmos e danças de origens europeias, sobretudo a polca. Há de se mencionar ainda um contexto cultural efervescente, marcado principalmente por reformas urbanas e suas consequências sociais e econômicas ${ }^{8}$.

\footnotetext{
6 Livre tradução do termo entrainment. A opção pelo termo embarcamento baseia-se na tradução literal do radical entrain como "embarcar". Semanticamente, o termo embarcar aparece na presente discussão como sinônimo de ingressar em algo ou mesmo de deixar-se levar. É como se, por meio da performance, os músicos possuíssem a capacidade de embarcar na sincronia de outros músicos, deixando-se levar pelas múltiplas relações que os processos sincrônicos podem desencadear. 0 termo também foi traduzido por Beatriz Raposo de Medeiros (2009, p.58) como "integração" ou "carreamento".

7 A lista de autores que abordam a história do choro é vasta e compreende trabalhos com diferentes orientações teóricas: desde a organização de dados e apresentação de fatos documentais - Cazes (2010) e Diniz (2007) - até a historiografia crítica - Bessa (2010) e Lima Rezende (2014) -, passando inclusive pela análise do discurso - Aragão (2013). 
Ao longo de aproximadamente 150 anos de história, o choro atravessou diferentes fases e se adaptou aos mais variados contextos: adquiriu reconhecimento social e se profissionalizou (BESSA, 2010, p.34); oscilou entre o centro e a margem da indústria fonográfica até cair no ostracismo (LIVINGSTON-ISENHOUR; GARCIA, 2005, p.88-98); e chegou a experimentar um verdadeiro boom durante a revitalização da década de 1970 (SOUSA, 2009, p.31-36). Estas passagens tornam a história desta música rica e extensa, caracterizando um tema à parte. Entretanto, é de interesse do presente texto destacar que a roda esteve presente em todos os momentos dessa trajetória, desde o surgimento até os dias atuais, chegando a ser considerada a "matriz" do choro (LARA FILHO et al., 2011 p.50). Diante da importância histórica e social, as rodas passaram a ser entendidas por mim como espaços informais destinados à performance musical, onde o choro é (e sempre foi) praticado (BERTHO, 2015, p.46).

Em linhas gerais, uma roda de choro é conduzida por um grupo base, quase sempre formado por músicos que desempenham as funções harmônica, melódica e rítmica ${ }^{9}$. Uma vez consolidado o grupo base, podem haver revezamentos com músicos profissionais ou amadores que frequentam o espaço onde esta prática acontece, geralmente em um bar ou restaurante. Entretanto, para participar desses revezamentos é necessário desenvolver previamente vários conteúdos: habilidades técnicas necessárias para tocar um instrumento; aquisição de conhecimento musical - principalmente o conteúdo associado ao choro, como as gravações de referência, a forma musical empregada, os tipos de fraseado mais utilizados, as variações rítmicas possíveis entre outros conteúdos; por fim, é imprescindível que o(a) interessado(a) em participar da roda compreenda os códigos sociais e morais que orientam a prática musical.

Diante das características expostas até aqui, o choro pode ser compreendido como uma música instrumental desafiadora. A dificuldade técnica presente no fraseado dos solistas, bem como as complexas conduções e variações de padrões rítmicos empregados pelos violões, pandeiros e percussões, requer dedicação constante por parte dos instrumentistas, que são desafiados a superar tais obstáculos por meio do estudo, da dedicação e do engajamento. Se, por um lado, a participação na roda de choro requer seriedade e comprometimento, por outro, é possível observar que, desde os momentos iniciais da roda, como a chegada dos participantes, até as escolhas das músicas que serão tocadas, temos um vigoroso processo de interação. O resultado é um grupo de pessoas altamente comprometidas com uma música interagindo das mais variadas formas para que o choro possa ser tocado nesse formato.

9 No choro, geralmente essas categorias dividem-se em instrumentos solistas (flauta, bandolim, clarinete, saxofone, entre outros) e acompanhadores (violão de seis cordas, violão de sete cordas, cavaco, pandeiro e variadas percussões). Existe ainda o uso da voz, no entanto, poucos choros possuem letra, o que torna esta prática pouco usual. 


\section{4-) Dinâmicas, propostas e revezamentos: alguns apontamentos etnográficos ${ }^{10}$}

Por volta de 20 h10 de uma terça-feira, os músicos começam a chegar no Almanach Bar e Restaurante. A esta altura já estão presentes os primeiros clientes, que frequentam o bar pelos mais variados motivos ${ }^{11}$. $O$ espaço que a roda ocupa neste estabelecimento, definido aqui como sala de música (Figura 4), acomoda aproximadamente oito mesas e uma média de quinze pessoas. Os músicos participantes da roda preferem tocar nesta sala por conta da acústica, haja vista que, nos outros ambientes, as conversas e gargalhadas do público chegam a ponto de comprometer a sonoridade dos instrumentos.

A sala de música, por sua vez, proporciona um ambiente intimista, no qual os músicos e o público se sentam próximos uns aos outros. Dada esta proximidade, os interessados em ouvir choro com maior clareza administram o volume de suas conversas, o que torna a sala de música um ambiente propício - nem sempre ideal - à acústica dos instrumentos ${ }^{12}$.

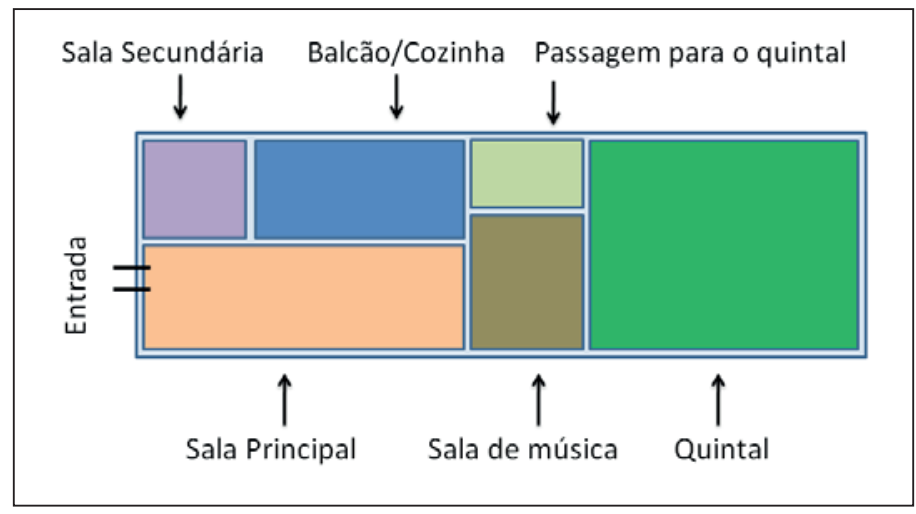

Figura 1: Representação do espaço físico do bar.

Decerto que podem ocorrer exceções para a utilização da sala de música, como na terça-feira 24/9/2013, data na qual este local foi reservado para aproximadamente 12 pessoas. Mediante a falta de espaço para a realização da roda, os músicos foram transferidos para a sala principal, e de imediato foi possível notar como a acústica do ambiente influenciou o fazer musical, conforme registrado em um trecho do meu diário de campo:

\footnotetext{
10 Gostaria de agradecer a todos os músicos que participaram direta ou indiretamente desta pesquisa. A reflexão aqui produzida só foi possível graças a ajuda e a paciência de vocês. Em especial, reitero o agradecimento aos que possuem seus nomes citados: Alcides Cardoso, Flávia Prazeres, Keila Yonashiro, Maurício Tagliadelo, Ricardo Cury e Tiago Veltrone. Que este artigo seja também um registro dos sons, das emoções e dos conhecimentos compartilhados em cada roda de choro.

11 Dados presentes em um questionário aplicado ao público revelaram que, das vinte e duas pessoas que responderam ao questionário, dez estavam no estabelecimento por conta da roda de choro, enquanto que cinco por conta das opções do cardápio e sete frequentavam o bar por outros motivos (a maioria para encontrar amigos).
} 
Como a acústica na sala principal é ruim e o bar estava muito movimentado, os músicos não conseguiam se escutar. A alternativa foi um revezamento dos solos entre flauta e saxofone, bem como a escolha por choros mais "fortes e rápidos". Poucos choros foram tocados inteiramente no bandolim, isso por conta da baixa potência sonora deste instrumento.

Ao abordar este assunto meses depois, em 12/11/2013, durante entrevista com o violonista Maurício Tagliadelo, surgiu a discussão sobre os fatores que influenciam os jeitos de tocar:

Renan - O público também influencia no jeito de tocar?

Maurício - Então, você tem que dançar conforme a música. Se o pessoal está falando muito alto, não adianta querer tocar um choro lento e livre, com a primeira parte sem pandeiro. Tem que ser tudo pra frente.

A influência do contexto geral de produção sonora nas características de uma determinada performance pode ocorrer em variadas manifestações ${ }^{13}$. Baseado em minha experiência etnográfica, observo que, em relação ao choro, o comportamento do público, bem como as características do lugar, podem orientar a escolha do repertório e afetar a performance dos músicos. Diante desta situação, compreendo que tocar choro em uma roda acústica num bar é estar imerso na dualidade entre se fazer ouvir e escutar quem toca ao seu lado.

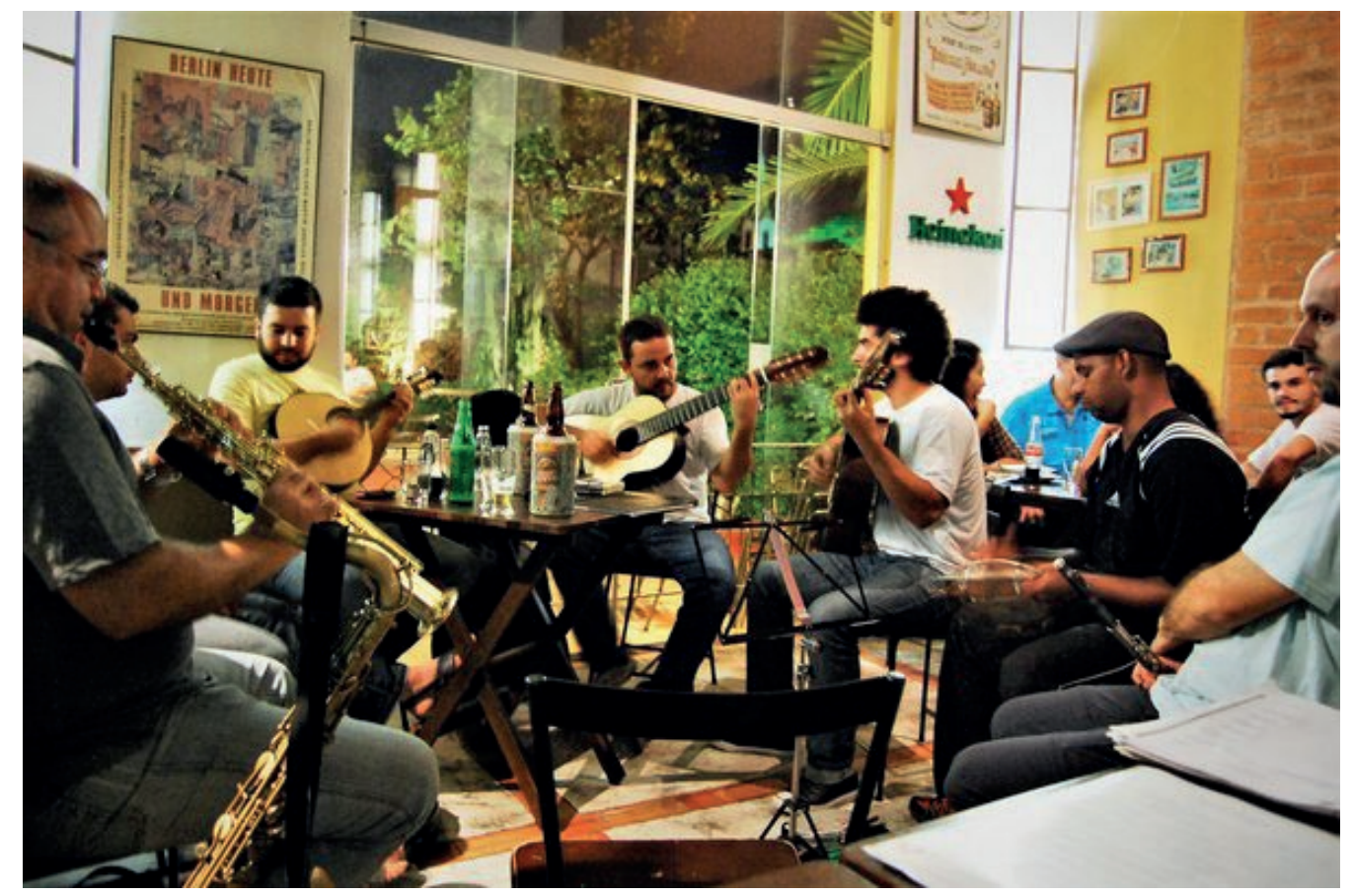

Foto1. Músicos na sala de música (29/1/2013). Fonte: foto do autor. pendendo das características acústicas das salas de concerto, até mesmo os solistas podem realizar "micro justes e nuances de interpretação", tais como alterações de andamento, mudanças na dinâmica e variações de articulação. 


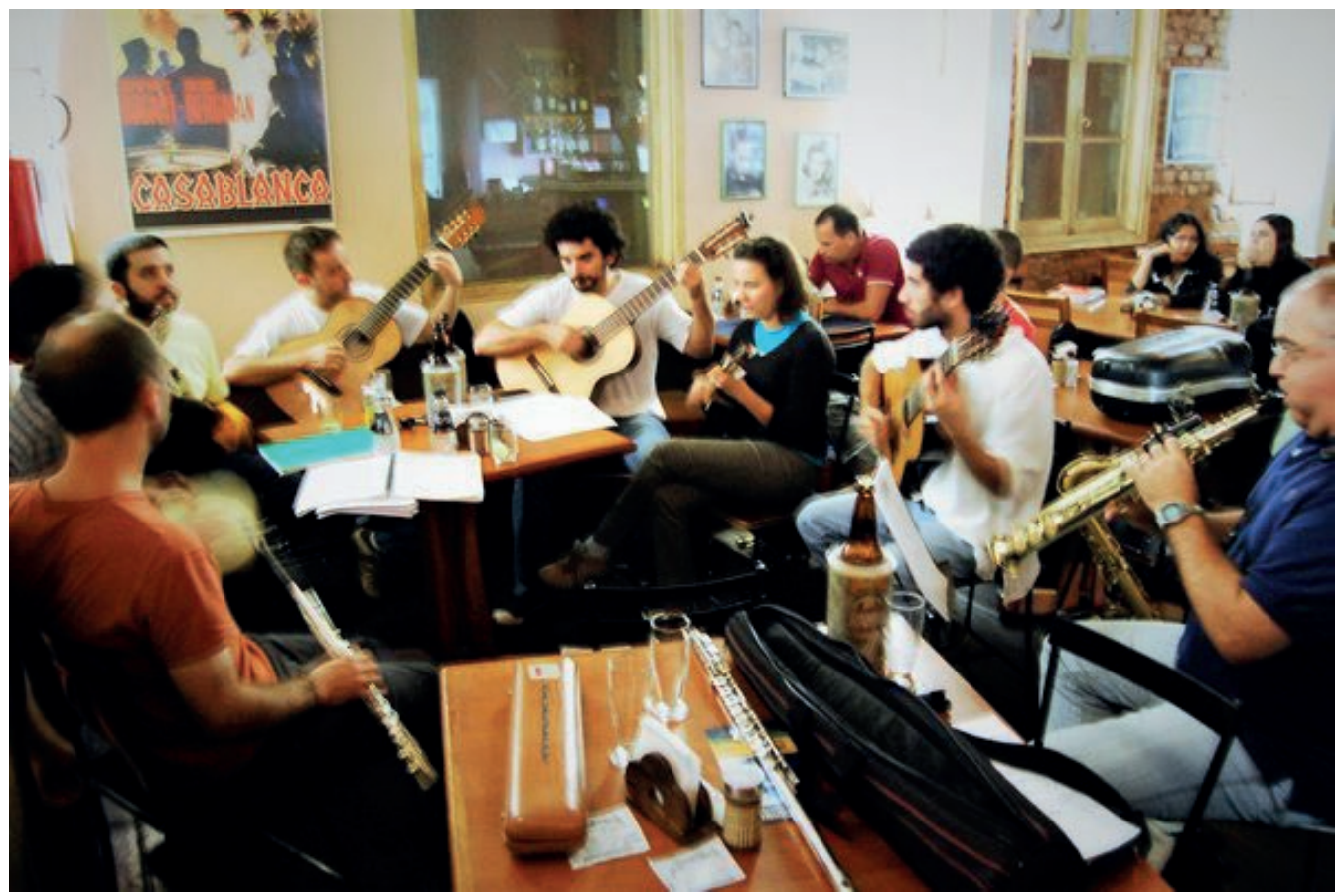

Foto 2. Músicos na sala principal (9/04/2013). Fonte: foto do autor.

Os primeiros músicos a chegar geralmente são os três integrantes do núcleo fixo; se por acaso houver atraso ou ausência, é necessário garantir a presença de um substituto para desempenhar a devida função, seja ela harmônica, melódica ou rítmica. Esta simples organização é essencial, pois garante os elementos musicais necessários para que o choro seja tocado. Após os cumprimentos e as saudações iniciais, os músicos sentam-se em volta de uma mesa. Neste momento observo que, quase sempre, os integrantes do núcleo fixo ocupam os mesmos lugares, ou seja, da esquerda para direita, temos o pandeirista Ricardo Cury, o bandolinista Tiago Veltrone e o violonista Maurício Tagliadelo. Entendo essas escolhas como uma demonstração da necessidade que os músicos possuem de ouvir com clareza e precisão uns aos outros, pois não há amplificação para os instrumentos, e o próprio ambiente do bar pode atrapalhar a performance. Em vista destas condições, temos a escuta como um elemento tão essencial quanto hierárquico, pois, ao se sentarem juntos para se escutar (e consequentemente assegurar as sessões rítmica, melódica e harmônica), os três músicos reafirmam suas identidades como pertencentes ao núcleo fixo.

Sentados nos respectivos lugares, os músicos dão início ao processo de afinação dos instrumentos, geralmente mediado por afinadores eletrônicos ou por aplicativos de celular que desempenham esta função. Tal processo não é exclusivo do começo da roda e pode aparecer sempre que necessário. Conversas variadas fazem parte deste momento. 


\subsection{Propostas}

Em meio ao processo de afinação, surgem as primeiras propostas musicais, entendidas neste artigo como ideias sonoras que carregam a intenção de comunicar aquilo que se deseja tocar. Geralmente são poucas notas, que em alguns casos pertencem à anacruse ${ }^{14}$, e em outros são frases da melodia principal. $O$ importante nessa situação é que estas notas sejam suficientes para proporcionar aos demais a identificação de qual música é proposta. No caso de um instrumento melódico, esta proposta aparece no formato de uma frase musical com duração de alguns compassos. Já nos instrumentos harmônicos, esta proposta pode surgir como uma frase musical ou ainda na forma de um encadeamento de acordes tocado dentro de uma levada. Quanto aos instrumentos de percussão, é possível que a ideia musical seja proposta através da marcação com acentuações características de um ritmo. Nestes casos, o percussionista comunica a intenção de tocar um ritmo específico, ficando a cargo do solista definir qual será a música a ser tocada dentro das especificidades deste ritmo. Exemplo: se a proposta musical for uma levada de maxixe, o solista pode optar por tocar Cheguei, Os Oito Batutas ${ }^{15}$, entre outras músicas que se enquadram neste ritmo. Caso o percussionista opte por uma música específica, é necessário comunicar verbalmente aos demais: "Vamos tocar o Cheguei?".

Observo que as formas verbais para solicitar um choro são frequentemente utilizadas pela maioria dos participantes. Classifico-as em duas categorias: argumentações e negociações. As argumentações partem de elementos morais e emotivos que o músico proponente utiliza para convencer os outros integrantes, por exemplo: "Vamos tocar Aeroporto do Galeão ${ }^{16}$ ? Gosto muito dela e faz tempo que não tocamos. Já pensou se eu esqueço esta música?" ou "Esta aqui o Jacob do Bandolim gravou! É muito boa, vamos tocar agora?". Já as negociações acrescentam elementos de troca aos momentos de escolha das músicas: "Tudo bem se tocarmos Aeroporto do Galeão daqui a pouco? Acontece que já tinham pedido para fazermos Cadência"17.

Os padrões de proposta musical e as categorias de argumentação e negociação caracterizam os modelos utilizados para definir o repertório democraticamente ao longo de toda prática. Logo, estes padrões estão presentes do início até o final da roda, de maneira aleatória e sem ordem preestabelecida ou sequência de músicas a ser seguida. Estes modelos podem ser simultâneos a outras ações, sendo que algumas vezes as propostas podem ser descartadas, passar despercebidas ou entrar em conflito (quando dois integrantes sugerem choros diferentes ou quando um dos músicos se recusa a tocar o choro escolhido). Nesses casos, a solução fica a cargo de algum integrante do núcleo fixo, que utiliza a argumentação e a negociação para decidir quais serão as próximas músicas.

\footnotetext{
$14 \quad$ Notas que precedem o tempo forte do primeiro compasso da música.

15 Ambas composições de Pixinguinha.

16 Choro composto por Altamiro Carrilho.

17 Choro composto por Rossini Ferreira.
} 
Os modelos de escolha do repertório revelam um processo coletivo e informal que é orientado por uma característica específica: não repetir músicas que já foram tocadas. Deste modo, quando um músico chega após o início da roda e solicita músicas que já foram tocadas, os participantes presentes desde o início avisam ao recém-chegado que o choro já foi apresentado. Entretanto, ocasiões internas e externas à roda podem alterar este padrão: as ocasiões internas acontecem quando um músico argumenta que deseja repetir a música com uma finalidade específica, que pode ser desde seu desenvolvimento pessoal (estudo), até a apresentação do tema para alguém que não estava na primeira vez que o choro foi tocado. A ocasião externa ocorre quando o público solicita que um choro seja tocado - essa solicitação pode ser verbal ou escrita; neste caso, são utilizados guardanapos para escrever o nome da música que se deseja ouvir.

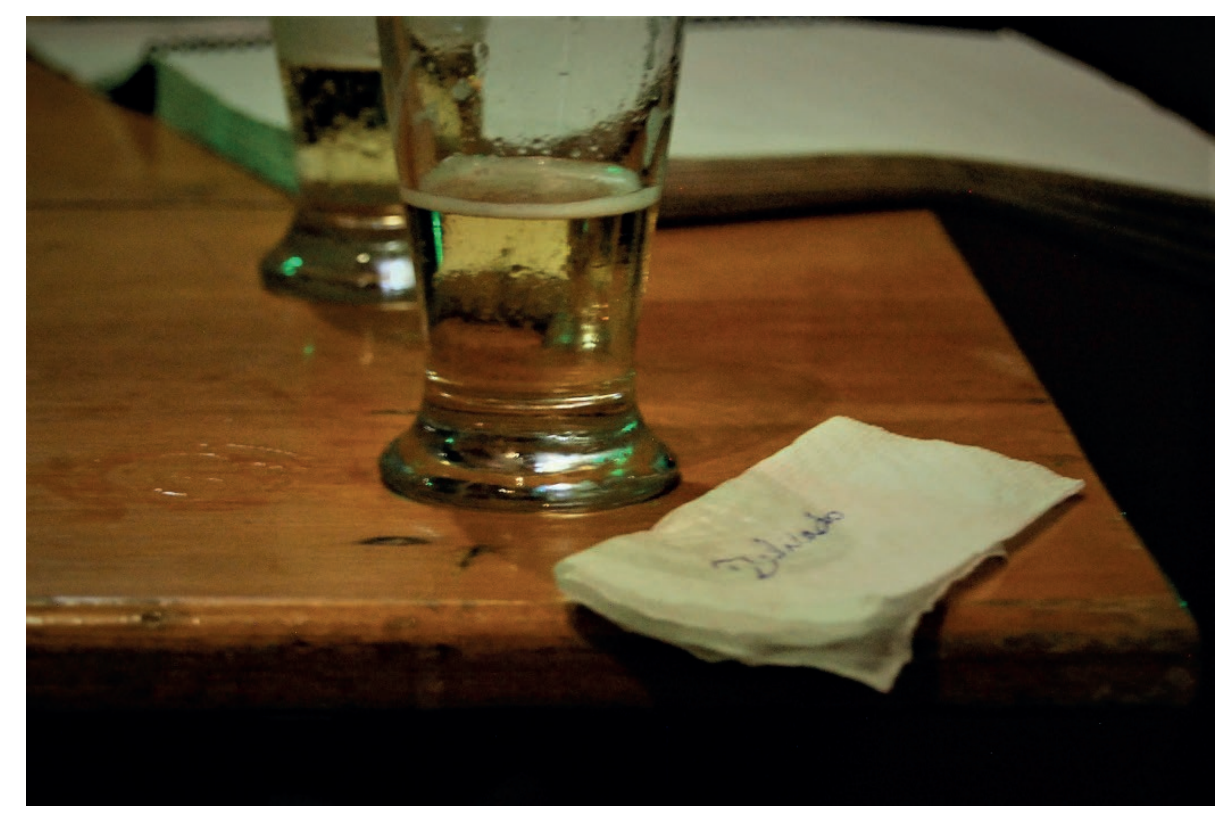

Foto 3. Bilhete sobre a mesa com sugestão da música Delicado, composta por Waldir Azevedo (24/12/2014). Fonte: foto do autor.

Uma vez que a música é definida, faz-se necessário determinar o andamento e a maneira como o choro começará. Neste ponto, ressalto três possibilidades de iniciar a música escolhida:

- Contagem: "1, 2, 1, 2, 1, 2", com ênfase no andamento. Este modelo é utilizado principalmente nos choros em que as sessões rítmica, melódica e harmônica começam juntas, ou quando a anacruse é insuficiente para determinar o andamento. 
- Enunciado: "Vai, agora é o Ansiedade"18 Anuncia o título da música que irá começar, porém o andamento é sugerido nas notas da anacruse, que nestes casos é suficiente para determinar o momento em que as demais sessões devem começar. O enunciado é utilizado principalmente quando há muitos músicos presentes e/ou diversas sugestões do que tocar. Nessas situações, é necessário reafirmar qual música foi escolhida para garantir que todos comecem na mesma música.

- Proposta musical: A fala que enuncia o título da música é substituída por um dos modelos de proposta musical explicados anteriormente.

Essas possibilidades podem se intercalar, como quando há o enunciado e a contagem; tudo depende da música escolhida e do contexto geral. Observo ainda que os instrumentistas envolvidos neste processo estão seguros de que todos os participantes tocam a música selecionada no mesmo tom. Esta certeza evita dúvidas e conflitos em relação à tonalidade. Feita a descrição de como os músicos chegam ao bar, ocupam seus respectivos lugares, afinam os instrumentos, escolhem as músicas e iniciam as mesmas, cabe observar como o choro é tocado na roda.

\subsection{Revezamentos}

A participação dos músicos na roda é orientada por revezamentos, que abrangem desde situações de substituição de um instrumentista até a troca de solistas durante a performance de uma música. Os revezamentos são frequentes e, dependendo da situação, podem ser previamente combinados ou totalmente espontâneos e dinâmicos. Diante dessas possibilidades, o presente tópico é dividido em duas partes: a primeira evidencia as trocas que geralmente acontecem no intervalo entre um choro e outro; a última parte apresenta situações que descrevem o revezamento dinâmico dos instrumentistas em momentos específicos no decorrer de um determinado choro.

\subsubsection{Trocas de instrumentos (ou "um pandeiro de cada vez")}

Quando Ricardo (pandeirista e membro do núcleo fixo) se ausenta da roda, todos os presentes olham para a percussionista Keila, que prontamente afina seu próprio pandeiro e assume a função de pandeirista oficial. Alguns minutos se passam, Ricardo retorna ao seu lugar e começa a tocar percussão. Enquanto isso, Keila continua tocando pandeiro. Passados três choros, ela propõe que eles voltem às funções anteriores. Ele assume novamente o pandeiro e ela a percussão. 
Esta situação, observada no dia 27/8/2013 e adaptada de um registro do meu diário de campo, ilustra a troca simultânea de instrumentos e funções entre os participantes. Tal característica foi observada em praticamente todas as rodas, ou seja, Ricardo e Keila revezavam constantemente o pandeiro e outros instrumentos de percussão. $O$ pandeiro é considerado a base rítmica da roda; a percussão, por sua vez, executa uma função complementar à do pandeiro. Nas palavras de Ricardo: "Se tiver algum outro cara que toca pandeiro, eu faço alguma percussãozinha só como acompanhamento, é uma coisa leve, porque a base do choro é o pandeiro" (Trecho da entrevista realizada no dia 26/2/2014). Esta fala enfatiza uma importante característica da roda: só é permitido que um pandeiro toque em cada música. Tal postura visa o equilíbrio, pois a potência sonora do pandeiro é muito superior à de instrumentos como o bandolim, por exemplo. Nesta situação específica, podemos dizer que o ato de tocar o pandeiro define a função do participante enquanto pandeirista principal, ou seja, o revezamento dos instrumentos (pandeiro/percussão) é simultâneo ao revezamento das funções (pandeirista/percussionista).

Revezamentos ocorrem a qualquer momento e envolvem todos os participantes em diversas funções. Em relação aos instrumentos de percussão, é importante acrescentar que, além do pandeiro, podem figurar na roda o tamborim, os blocos de madeira e o reco-reco, bem como a inexistência dos mesmos. Diferentemente da restrição ao uso de mais de um pandeiro, duas ou mais percussões podem tocar ao mesmo tempo, entretanto é preciso discernimento para escolher a mais coerente e conhecimento para tocar de maneira apropriada ${ }^{19}$.

Independentemente de envolver violão, pandeiro ou percussão, os revezamentos que apresentam simultaneidade na troca de instrumentos e funções trazem alterações na sonoridade, na performance e no repertório. A sonoridade é alterada por conta da mudança de instrumento - Keila, por exemplo, opta por usar seu próprio pandeiro ao invés do instrumento tocado por Ricardo. Já a performance é amplamente repensada, pois os jeitos de tocar variam de acordo com as possibilidades sonoras de cada instrumento e com o domínio técnico musical dos instrumentistas; se um participante tocar percussão muito forte, os demais terão que aumentar a intensidade para serem ouvidos. O repertório, por sua vez, é repensado com base nas características idiomáticas de cada instrumento. Quando se trata do revezamento na função de solista, por exemplo, esta questão é expressa através de frases como: "Esse é um choro de flauta, fica estranho tocar no bandolim"20.

\footnotetext{
19 O conhecimento e o discernimento mencionados aqui são frutos do estudo de um determinado instrumento, da experiência de tocar com outras pessoas e da escuta das gravações de referência. No artigo "Gravações performadas: material fonográfico e aprimoramento técnico em uma roda de choro" (BERTHO, 2018), por exemplo, abordo a relação entre os músicos que participam de rodas de choro e as gravações que Ihes influenciam nos âmbitos moral, estético e ideológico.

20 "Choros de flauta" geralmente são composições de flautistas, como Altamiro Carrilho, Joaquim Callado, para citar alguns. Semelhante raciocínio é aplicado aos "choros de bandolim", "choros de cavaquinho", entre outros que são definidos a partir do instrumento tocado pelo compositor. Estas especificidades são utilizadas mais como definição do gosto pessoal do solista ("fica estranho tocar") do que como regra geral para determinar a participação.
} 


\subsubsection{Revezamento dinâmico de funções (ou "cada um faz uma parte")}

Até o presente momento enfatizei os revezamentos de funções que ocorrem simultaneamente às trocas de instrumentos. Resta observar as situações nas quais os integrantes alternam entre diferentes papéis sem necessariamente revezar instrumentos, a estes atribuo o nome de revezamentos dinâmicos de funções. Para compreendermos esta possibilidade, é necessário explicar de antemão as estruturas e formas musicais presentes na roda. De modo geral, o repertório praticado é dividido em sessões, quase sempre de 16 compassos, intituladas "partes". Os choros podem possuir duas ou três partes, identificadas como $A, B$ e $C$, que se repetem e se intercalam de maneira estruturada. Em um choro de três partes, por exemplo, temos a estrutura A-A'-B-B'-A'-C$C^{\prime}-A^{\prime \prime \prime}$, denominada forma rondó ${ }^{21}$. De acordo com Moura (2012, p.21), esta maneira seccional de distribuir as partes e retornar ao tema principal teve origem na Idade Média e está presente no choro desde o final do século XIX.

A relação entre a forma musical e o revezamento dos integrantes é de suma importância, pois, ao final de cada parte, é possível acrescentar ou retirar instrumentos. Nos revezamentos dinâmicos estas alterações envolvem instrumentistas na função de solista e são propostas no final de cada parte, geralmente no décimo quinto compasso:

Os participantes aceitam minha sugestão de tocarmos Chorando baixinho ${ }^{22}$. Inicio a música e nos últimos compassos da parte A olho para Tiago, que toca a harmonia no bandolim. No ato de olhar tenho a intenção de confirmar se ele irá solar a próxima parte. Ele compreende a minha dúvida e faz um sinal de negativo com a cabeça. Toco as primeiras notas do primeiro compasso da parte $A^{\prime}$ e sou surpreendido por um dedilhado de cordas em uníssono à melodia que toco na flauta. Olho para o lado e percebo que Flávia, que até então tocava a harmonia, começa a solar esta parte no cavaco.

Tal situação, que ocorreu no dia 11/11/2014, é apresentada aqui como uma adaptação dos dados registrados em diário de campo. Os olhares e os sinais com a cabeça representam algumas das atitudes corporais que podem ser ressignificadas e, no caso desta situação específica, auxiliam na comunicação constante entre o solista em exercício (aquele que está tocando a melodia) e os solistas em potencial (instrumentistas que possuem habilidades específicas para executar a melodia de qualquer uma das partes).

Salvo algumas exceções, o padrão observado é de apenas um solista em exercício a cada parte, logo, o revezamento com os solistas em potencial é constante e ocorre sempre na transição de uma parte para outra do choro. Estas características orientam a performance na situação descrita anteriormente. Vale lembrar que, enquanto Flávia e Tiago ocupavam a posição de solistas em potencial, eu estava desempenhando a função de solista em exercício. Ao terminar a primeira parte da música, as funções se inverteram, e continuaram a se inverter sucessivamente, de modo que a cada parte temos 
um participante ocupando a função de solista em potencial: A- Renan / A'- Flávia / BRenan / B'- Flávia / A" - Renan / C- Flávia / C"'- Renan / A"'- Flávia. Revezamentos desta natureza demandam concentração e comunicação por parte dos envolvidos, pois, se ao final de uma parte o solista em exercício parar de tocar (tendo a impressão de que será substituído), é imprescindível que o próximo comece a tocar imediatamente. Em outras palavras, este revezamento precisa ser dinâmico e eficaz, caso contrário, a sonoridade geral será prejudicada, pois levará alguns compassos para que o solista anterior retome esta função.

Enquanto os solistas participam deste revezamento, os demais participantes continuam a tocar seus instrumentos de acordo com suas respectivas funções. A tabela 1 apresenta um panorama da instrumentação em um choro de três partes com dois solistas, ambos alocados na seção melódica e alternando sistematicamente entre o papel de solista em exercício (assinalados com $X$ nas colunas pertencentes à seção melódica) e solista em potencial (células vazias nas mesmas colunas) ${ }^{23}$.

Nesta tabela, a letra $X$ representa os instrumentos que tocam em cada parte, e $Y$ os instrumentos que podem ou não tocar na parte indicada. A percussão, por exemplo, não precisa necessariamente ser tocada nas primeiras vezes de cada parte (A, B e $C$, sinalizadas com $Y$ ), mas espera-se que esteja presente na última parte. A flauta, por sua vez, não tocaria na parte $A^{\prime \prime \prime}$ - momento no qual o cavaco assume o papel de solista em potencial -, entretanto a última parte é uma exceção, pois dois ou mais instrumentos podem tocar o solo simultaneamente em uníssono e enfatizar a intenção de final.

\begin{tabular}{|c|c|c|c|c|c|c|c|}
\hline \multirow{3}{*}{ Parte } & \multicolumn{7}{|c|}{ Distribuição e revezamento de funções de acordo com a forma musical I } \\
\hline & \multicolumn{2}{|c|}{ Seção melódica } & \multicolumn{3}{|c|}{ Seção harmônica } & \multicolumn{2}{|c|}{ Seção rítmica } \\
\hline & Flauta & Cavaco & Cavaco & Bandolim & Violão & Percussão & Pandeiro \\
\hline A & $\mathrm{X}$ & & $\mathrm{X}$ & $\mathrm{X}$ & $\mathrm{X}$ & Y & $X$ \\
\hline$A^{\prime}$ & & $\mathrm{X}$ & & $\mathrm{X}$ & $\mathrm{X}$ & $\mathrm{X}$ & $\mathrm{X}$ \\
\hline B & $\mathrm{X}$ & & $x$ & $x$ & $x$ & $Y$ & $x$ \\
\hline$B^{\prime}$ & & $X$ & & $x$ & $x$ & $x$ & $x$ \\
\hline$A^{\prime \prime}$ & $x$ & & $X$ & $x$ & $x$ & $x$ & $x$ \\
\hline C & & $x$ & & $x$ & $x$ & $Y$ & $x$ \\
\hline$C^{\prime}$ & $x$ & & $x$ & $x$ & $x$ & $x$ & $x$ \\
\hline$A^{\prime \prime \prime}$ & $Y$ & $x$ & $Y$ & $x$ & $x$ & $X$ & $x$ \\
\hline
\end{tabular}

Tabela 1. Distribuição e revezamento de dois solistas

23 Nas tabelas 1 e 2 optei por agrupar os instrumentos de acordo com suas respectivas funções em cada seção. Por exemplo, a seção harmônica é composta por cavaco, bandolim e violão, todos envolvidos com as funções de acompanhamento harmônico. Entretanto, o cavaco também ocupa a função de solista, logo sua presença também na seção melódica. Minha intenção é facilitar a compreensão das situações de revezamento e não aprofundar questões organológicas com base nas características físicas e sonoras de cada instrumento. 
O modelo representado na Tabela 1 corresponde a um revezamento dinâmico de função entre dois solistas. Contudo, outras possibilidades podem surgir como na representação abaixo, na qual o bandolim divide o solo com o cavaco e com a flauta:

\begin{tabular}{|c|c|c|c|c|c|c|c|c|}
\hline \multicolumn{7}{|c|}{ Distribuição e revezamento de funções de acordo com a forma musical II } \\
\hline \multirow{2}{*}{ Parte } & \multicolumn{3}{|c|}{ Seção melódica } & \multicolumn{3}{c|}{ Seção harmônica } & \multicolumn{2}{c|}{ Seção rítmica } \\
\cline { 2 - 10 } & Flauta & Cavaco & Bandolim & Cavaco & Bandolim & Violão & Percussão & Pandeiro \\
\hline A & $\mathrm{X}$ & & & $\mathrm{X}$ & $\mathrm{X}$ & $\mathrm{X}$ & $\mathrm{Y}$ & $\mathrm{X}$ \\
\hline $\mathrm{A}^{\prime}$ & & $\mathrm{X}$ & & & $\mathrm{X}$ & $\mathrm{X}$ & $\mathrm{X}$ & $\mathrm{X}$ \\
\hline B & & & $\mathrm{X}$ & $\mathrm{X}$ & & $\mathrm{X}$ & $\mathrm{Y}$ & $\mathrm{X}$ \\
\hline B' $^{\prime}$ & $\mathrm{X}$ & & & $\mathrm{X}$ & $\mathrm{X}$ & $\mathrm{X}$ & $\mathrm{X}$ & $\mathrm{X}$ \\
\hline $\mathrm{A}^{\prime \prime}$ & & $\mathrm{X}$ & & & $\mathrm{X}$ & $\mathrm{X}$ & $\mathrm{X}$ & $\mathrm{X}$ \\
\hline C & & & $\mathrm{X}$ & $\mathrm{X}$ & & $\mathrm{X}$ & $\mathrm{Y}$ & $\mathrm{X}$ \\
\hline $\mathrm{C}^{\prime}$ & $\mathrm{X}$ & & & $\mathrm{X}$ & $\mathrm{X}$ & $\mathrm{X}$ & $\mathrm{X}$ & $\mathrm{X}$ \\
\hline $\mathrm{A}^{\prime \prime \prime}$ & $\mathrm{Y}$ & $\mathrm{X}$ & $\mathrm{Y}$ & $\mathrm{Y}$ & $\mathrm{Y}$ & $\mathrm{X}$ & $\mathrm{X}$ & $\mathrm{X}$ \\
\hline
\end{tabular}

Tabela 2. Distribuição e revezamento de três solistas

Quando três ou mais solistas em potencial tocam um choro com a forma rondó padrão, a quantidade de repetições é insuficiente para que todos assumam a função de solista em exercício nas três diferentes partes - é o caso do cavaco, que, no contexto ilustrado pela tabela, solaria apenas nas partes $A, A^{\prime}$ e $A^{\prime \prime \prime}$. Diante desta questão, a forma musical pode ser alterada, principalmente no que diz respeito a novas repetições que variam de acordo com o interesse e a necessidade dos participantes. Como demonstrado na seguinte situação, registrada em meu diário no dia 8/10/2013:

Decidimos começar a roda com Cadência ${ }^{24}$, e Alcides menciona que tocará essa música na roda pela primeira vez. Neste momento somos em três solistas: ele com o saxofone, Tiago com o bandolim e eu com a flauta. Ao final da última parte $B$, quando todos esperam retornar para parte $A$ final, Tiago olha à sua volta e solicita verbalmente uma nova repetição: "Faz mais um B!". Prontamente os outros integrantes atendem seu pedido e alteram a forma-padrão.

Cadência é um choro de duas partes, e a forma convencional de tocá-lo é $A-A^{\prime}-$ $B-B^{\prime}-A^{\prime \prime}-B^{\prime \prime}-A^{\prime \prime \prime}$. Porém, na situação descrita, Tiago propôs alterações que deixaram a música com a estrutura $A-A^{\prime}-B-B^{\prime}-B^{\prime \prime} A^{\prime \prime}-B^{\prime \prime \prime}-A^{\prime \prime \prime}$. A alteração causada pelo acréscimo da parte $B^{\prime \prime}$, antes da parte $A^{\prime \prime}$, permitiu que os três solistas em potencial pudessem tocar todas as partes. Aparentemente esta alteração foi orientada pela situação colocada inicialmente por Alcides, que tocava o choro pela primeira vez em público, logo era esperado que ele tivesse a oportunidade de tocar todas as partes. 
Alterações de forma ocorrem ainda quando os solistas em exercício improvisam a melodia que será tocada. Antes de prosseguir, convém esclarecer que neste texto os improvisos são entendidos de acordo com a definição de Cortes (2012, p.34), ou seja, uma construção rítmico-melódica elaborada em tempo real sobre uma sequência de acordes ou progressão harmônica preestabelecida. Nas palavras do autor:

Para a realização de tal improvisação, o músico utiliza todo o material musical que foi absorvido através de estudo prévio (citações de outras músicas, figuras rítmicas recursivas, fraseado relacionado do gênero em questão, dentre outras coisas). [...] Acredita-se que a improvisação reside na maneira de articular esses elementos no momento da performance, nas escolhas feitas pelo solista, nas conexões que ele realiza entre os elementos estudados e aquilo que o ouvinte espera como resultado final. (CORTES, 2012, p.35)

De volta à roda de choro, os improvisos quase sempre acontecem em choros específicos, como em Cochichando e Sonoroso ${ }^{25}$, e geralmente ficam restritos à parte C. Entretanto, após a parte B, o solista em exercício pode propor novas repetições em qualquer uma das partes, desde que comunique tais alterações aos demais participantes. Há ainda situações nas quais todos os instrumentistas improvisam. Neste caso, a função de solistas em potencial pode ser assumida por qualquer participante, e a parte a ser improvisada é repetida de acordo com o número de músicos dispostos a elaborar tais construções rítmico-melódicas. Uma característica a ser ressaltada é que, apesar destas variações e possibilidades, o choro só termina quando retorna à parte A, logo temos uma estrutura bem diferente da forma rondó padrão observada anteriormente:

$$
A-A^{\prime}-B-B^{\prime}-[B]-A^{\text {Anterior à parte } C}-C-C^{\prime}-[C]-A A^{\text {nterior à }[A]}-[A]-A^{\text {final }} \text {. }
$$

Por $[\mathrm{B}]$ compreendo as possíveis repetições da parte B para improvisar; [C], por sua vez, significa a possibilidade de repetir a parte $C$ para improvisar, e [A] representa os improvisos que podem acontecer em qualquer uma das três partes antes do $A^{\text {Final. }}$ [B], [C] e [A] são entendidas como possibilidades indeterminadas de repetição, pois a quantidade de vezes que serão repetidas fica a cargo do contexto geral e do participante que assumir a função de solista em exercício. Apesar de tamanha abertura, dificilmente estas partes são repetidas mais do que três vezes, pois o participante que improvisa permanece atento às condições de revezamento, visando dar oportunidade a todos os solistas em potencial.

Finalmente, sinalizo que o repertório praticado na roda possui uma forma padrão (A-A'-B-B'-A"-C-C'-A'"' no caso de um choro de três partes), que foi estabelecida ao longo do tempo e atualmente está presente na maior parte das gravações e apresentações de choro. Todavia, este padrão sofre alterações na roda, e estas são orientadas pelas possibilidades de improvisação e pelas características dos solistas em potencial, cada qual com suas argumentações (como no caso de Alcides em 8/10/2013). Logo, o que 
caracteriza o fazer musical na roda como uma performance participativa não é apenas a sua organização estrutural, mas também a flexibilização das dinâmicas coletivas de acordo com o contexto geral e ainda a possibilidade de acontecerem alterações de cunho musical tanto na forma quanto na instrumentação.

\section{Conclusão}

No presente artigo busquei demonstrar como interação e coletividade estão presentes na performance da roda de choro. Para tanto, apresentei dados etnográficos que ilustram as propostas de início de uma determinada música, bem como as dinâmicas de revezamento entre os participantes. Ao analisar estes dados, observo que as formas de colaboração e de interação entre os músicos da roda se dão desde a negociação do repertório - quando escolhem democraticamente qual música será tocada - até a maneira como se organizam para tocar - mesmo que esta maneira altere a forma rondó original dos choros. Estes elementos ajudam a compreender a roda sob uma perspectiva da coletividade e demonstram que os choros tocados nesse ambiente podem estar sujeitos, por exemplo, às variações de dinâmica, de instrumentação e de forma. Em suma, acredito que estas alterações são consequências do contexto geral de produção sonora e visam aspectos de melhoria e de otimização da performance, seja no momento de "tudo pra frente" - para que todos possam se escutar sem serem prejudicados pelas conversas do público - , seja no momento de acrescentar uma parte à forma original da música - para que assim todos possam tocar e/ou improvisar.

Teoricamente, observo que John Blacking, Anthony Seeger, Suzel Reily e Martin Calyton abordam diferentes aspectos das práticas musicais coletivas. Cada autor apresenta uma especificidade sobre os modos e as possibilidades de fazer música em conjunto, demonstrando assim a pertinência da coletividade para etnomusicologia. Não por acaso, muitos dos aspectos apresentados por estes autores encontram correspondência e aplicabilidade nas rodas de choro. Neste sentido, as diferentes formas de revezamento entre músicos e instrumentos da roda de choro se aproximam dos aspectos descritos por Blacking na tshikona, uma vez que se tratam de ações coletivas coordenadas; metaforicamente, as propostas e as possibilidades de início de cada choro associam-se à "euforia da participação comunitária", como descrito por Seeger; já o comprometimento, a seriedade e a dedicação que os músicos demonstram ao encarar a dinâmica roda de choro é correspondente à esfera da moral e da divindade, tais quais colocadas por Reily; finalmente, os momentos de coordenação mútua entre diferentes músicos - como quando um instrumentista olha para o outro na intenção de confirmar um revezamento - contemplam requisitos de um embarcamento interindividual, pois carece de um intenso processo de sincronização entre os instrumentistas envolvidos. 


\section{Bibliografia}

ARAGÃO, Pedro. O Baú do Animal: Alexandre Gonçalves Pinto e O Choro. Rio de Janeiro: Folha Seca, 2013

BERTHO, Renan Moretti. Academia do choro: performance e fazer musical na roda. Dissertação (Mestrado em Música) - Instituto de Artes, Universidade Estadual de Campinas, Campinas, 2015.

Gravações performadas: material fonográfico e aprimoramento técnico em uma roda de choro. Tulha, Ribeirão Preto, v. 4, n. 2, p. 215-227, jul./dez. 2018

BESSA, Virgínia de Almeida. A escuta singular de Pixinguinha: história e música popular no Brasil nos anos 1920 e 1930. São Paulo: Alameda, 2010.

BLACKING, John. How musical is man? 6. ed. Seattle: University of Washington Press, 2000, 1973.

Music, Culture, and Experience. Selected Papers. BYRON, Reginald (Ed.). Chicago: University of Chicago Press, 1995.

CAZES, Henrique. Choro: do quintal ao Municipal. 4. ed. São Paulo: Editora 34, 2010.

CHAFFIN, R.; LEMIEUX, A. F.; CHEN C. Spontaneity and Creativity in Highly Practised Performance. In: DELIĖGE; WIGGINS (Eds.). Musical Creativity. Hove and New York: Psychology Press, 2006. p. 200-2018.

CLAYTON, Martin. Entrainment, ethnography and musical interation. In: CLAYTON, Martin; DUECK Byron; LEANTE, Laura (Org.). Experience and Meaning in Music Performance. New York: Oxford University Press, 2013.

CONTIER, A. D. O nacional na música erudita brasileira: Mário de Andrade a questão da identidade cultural. Fênix, Uberlândia, v. I, p. 1-22, 2004.

CORTES, Almir. Improvisando em música popular: um estudo sobre o choro, o frevo e o baião e sua relação com a "música instrumental" brasileira. 2012. 285 f. Tese (Doutorado) - Instituto de Artes, Universidade Estadual de Campinas, Campinas, 2015.

DINIZ, André. O Rio musical de Anacleto de Medeiros: a vida, a obra e o tempo de um mestre do choro. Rio de Janeiro: Jorge Zahar, 2007. 
LARA FILHO, Ivaldo; SILVA, Gabriela; FREIRE, Ricardo. Análise do contexto da Roda de Choro com base no conceito de ordem musical de John Blacking. Per Musi, Belo Horizonte, n. 23, p. 148-161, 2011.

LIMA REZENDE, Gabriel S. S. O problema da tradição na trajetória de Jacob do Bandolim: comentários à história oficial do choro. Tese (Doutorado em Música) Instituto de Artes, Universidade Estadual de Campinas, Campinas, 2014.

LIVINGSTON-ISENHOUR, Tamara Elena; GARCIA, Thomas George Caracas. Choro: a social history of a Brazilian popular music. Bloomington: Indiana University Press, 2005.

MOURA, Rafael M. O toque de Midas do choro: estabilidade e fricção a luz das tópicas. Dissertação (Mestrado em Música) - Universidade de Brasília, Brasília, 2012.

RAPOSO de MEDEIROS, B. Ritmo na língua e na música: o elo possível. Música em Perspectiva, v. 2, p. 45-63, 2009.

REILY, Suzel. Voices of the Magi: enchanted jouneys in Southeast Brazil. Cambridge: Cambridge University Press, 2002.

SEEGER, Anthony. Por que cantam os Kĩsêdjê: uma antropologia musical de um povo amazônico. São Paulo: Cosac Naify, 2015.

SOUSA, Miranda Bartira Tagliari Rodrigues Nunes de. O Clube do Choro de São Paulo: arquivo e memória da música popular na década de 1970. Dissertação (Mestrado em Música) - Instituto de Artes, Universidade Estadual Paulista, São Paulo, 2009.

TRAVASSOS, Elizabeth. John Blacking ou uma humanidade sonora e saudavelmente organizada. Cadernos de Campo (São Paulo, 1991), Brasil, v. 16, n. 16, p. 191-200, mar. 2007.

WISNIK, Jose Miguel; SQUEFF, Enio. Música. 2. ed. São Paulo: Brasiliense, 1983. 